\title{
BEV CHARGING \\ BEHAVIOR OBSERVED \\ IN THE EV PROJECT \\ FOR 2013
}

Brion D. Bennett

January 2014

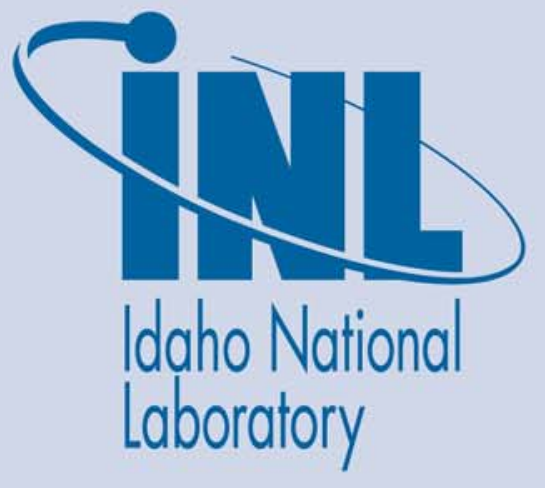

The INL is a U.S. Department of Energy National Laboratory operated by Battelle Energy Alliance 


\title{
BEV CHARGING BEHAVIOR OBSERVED IN THE EV PROJECT FOR 2013
}

\author{
Brion D. Bennett
}

January 2014

\begin{abstract}
Idaho National Laboratory
Idaho Falls, Idaho 83415
\end{abstract}

http://www.inl.gov

Prepared for the

U.S. Department of Energy

Office of Energy Efficiency/Renewable Energy

Under DOE Idaho Operations Office

Contract DE-AC07-05ID14517 
Nissan Leaf Charging Behavior Observed in The EV Project for 2013

Idaho National Laboratory (INL) - Report Number INL/EXT-14-33144

Region

All

Number of vehicles

4613

Reporting period

$1 / 1 / 2013-1 / 1 / 2014$

Vehicle Usage

Number of trips

Total distance traveled (mi)

160,376

Total number of charging even

$1,135,093.0$
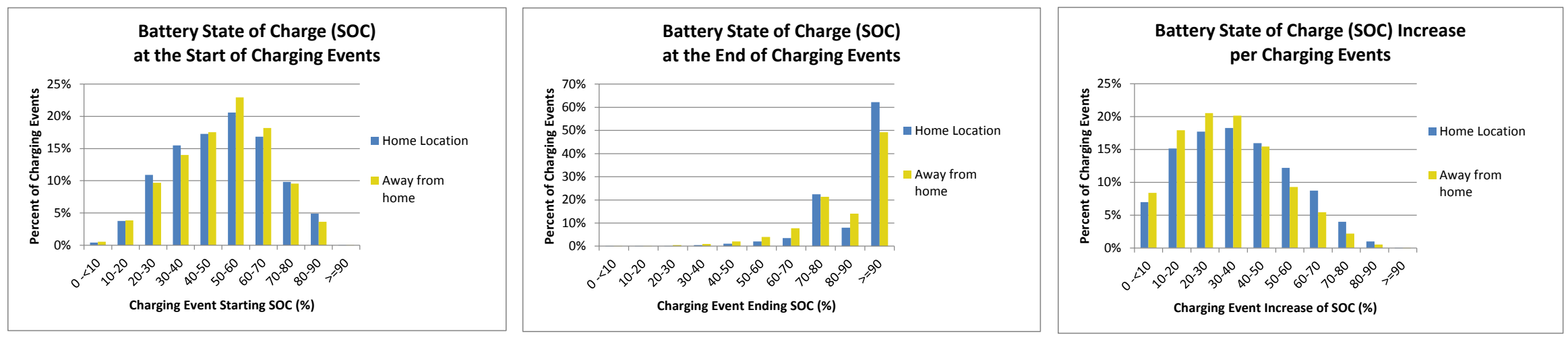

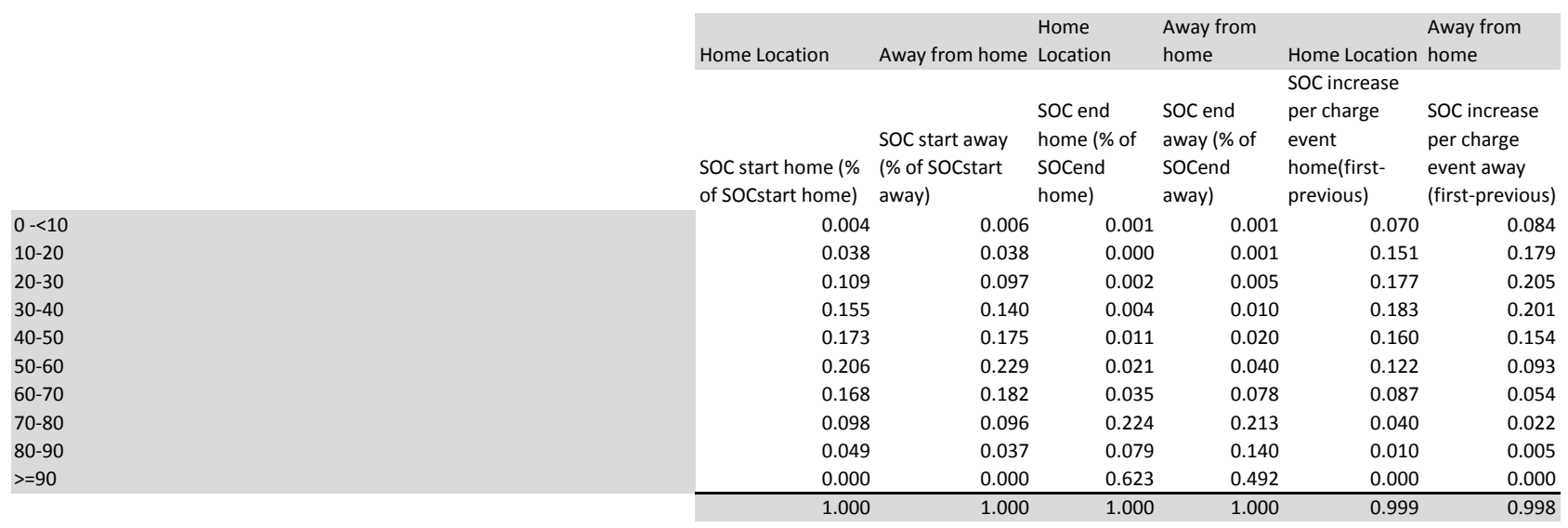

